\title{
Associação do Herbicida Tebuthiuron Com a Cobertura de Palha no Controle de Plantas Daninhas no Sistema de Cana-Crua ${ }^{1}$
}

\author{
Tebuthiuron and Straw Cover Association for Weed Control Under the Raw Sugar Cane System
}

\author{
NEGRISOLI, E. ${ }^{2}$, VELINI, E.D. ${ }^{3}$, ROSSI, C.V.S. ${ }^{4}$, CORREIA, T.M. ${ }^{5}$ e COSTA, A.G.F. ${ }^{6}$
}

\begin{abstract}
RESUMO - O objetivo da presente pesquisa foi verificar a eficácia do herbicida tebuthiuron no controle de plantas daninhas quando associadas à presença de palha de cana-de-açúcar. Para isso, conduziu-se um experimento em condições controladas em casa de vegetação, utilizando-se vasos com quatro repetições, onde, além das testemunhas com e sem palha, o tebuthiuron foi aplicado em diferentes situações: sobre $5 \mathrm{t}$ de palha ha- ${ }^{-1}$; sobre o solo posteriormente recoberto com $5 \mathrm{t}$ de palha ha ${ }^{-1}$; sobre o solo sem cobertura de palha; e com ou sem simulação de distintas quantidades de chuva aplicada antes ou após a aplicação do produto. A dose de Combine $500 \mathrm{SC}$ (tebuthiuron) aplicada foi de $1.000 \mathrm{~g}$ i.a. ha ${ }^{-1}$, com consumo de calda equivalente a $200 \mathrm{~L} \mathrm{ha}^{-1}$. As plantas daninhas presentes no experimento foram Brachiaria plantaginea, Brachiaria decumbens e Ipomoea grandifolia. Avaliou-se a porcentagem de controle das plantas daninhas aos $7,14,21,28,35,42,49$ e 56 DAA nos tratamentos em que o tebuthiuron foi aplicado em pré-emergência e aos $3,10,17,24,31$ e 38 DAA, quando o herbicida foi aplicado em pós-emergência; e a biomassa seca aos 56 ou 38 DAA. Verificou-se que, independen temente da planta daninha avaliada, os maiores índices de controle foram alcançados quando o tebuthiuron foi aplicado sobre a palha, simulandose em seguida precipitação correspondente a 2,5 ou $30 \mathrm{~mm}$ de chuva, e nos tratamentos em que o herbicida foi aplicado diretamente no solo desnudo ou recoberto com palha. Dessa forma, para I. grandifolia, $B$. plantaginea e $B$. decumbens, os índices mais elevados de controle foram alcançados quando o tebuthiuron atingiu o solo, tanto aplicado diretamente como quando lixiviado da palha pela chuva simulada após a aplicação.
\end{abstract}

Palavras-chave: herbicida, lixiviação, cana-crua, eficácia.

\begin{abstract}
The objective of this work was to evaluate the effectiveness of tebuthiuron associated with sugar cane straw to control weed under different conditions. Thus, an experiment was carried out in pots with four replications where, besides being applied with and without straw, tebuthiuron was applied on $5 \mathrm{t}$ straw $\mathrm{ha}^{-1}$; on soil recently covered with $5 \mathrm{t}$ straw hat $\mathrm{h}^{-1}$ and on soil without straw cover and with and without simulation of different amounts of rain applied before or after herbicide application. The rate of Combine 500 SC (tebuthiuron) applied was

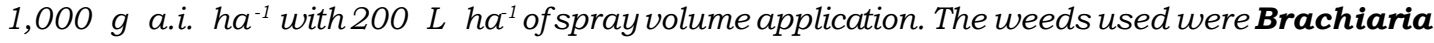
plantaginea, Brachiaria decumbens and Ipomoea grandifolia. Weed control percentage was evaluated at 7, 14, 21, 28, 35, 42, 49 and 56 days after application (DAA) when tebuthiuron was applied in pre-emergence; and at 3,10,17,24, 31 and 38 DAA when applied in postemergence; dry matter weight was evaluated at 56 and 38 DAA, respectively. Regardless of the weed assessed, it was verified that the highest control rates were reached when tebuthiuron was applied on the straw, after rainfall simulation corresponding to 2.5 or $30 \mathrm{~mm}$ or for the treatments
\end{abstract}

Recebido para publicação em 29.1.2007 e na forma revisada em 13.8.2007.

2 Eng--Agro., Dr., FCA/Unesp-Botucatu, SP. Fazenda Experimental Lageado, Caixa Postal 237, 18603-970 Botucatu-SP; ${ }^{3}$ Prof. Adjunto. Dep. Agricultura FCA/ Unesp - Botucatu-SP; ${ }^{4}$ Eng $^{\circ}-$ Agr $^{0}$. . M.Sc., FCA/Unesp-Botucatu, SP. Fazenda Experimental Lageado, Caixa Postal 237, 18603-970 Botucatu-SP; ${ }^{5}$ Engo-Agro-, M.Sc. em Agricultura. FCA/Unesp - Botucatu, SP. Fazenda Experimental Lageado, Caixa Postal 237, 18603-970. Botucatu-SP; ${ }^{6}$ Eng-9 Agr ${ }^{\circ}$., Dr., FCA/Unesp-Botucatu, SP. FazendaExperimental Lageado, Caixa Postal 237, 18603-970. Botucatu-SP.

Planta Daninha, Viçosa-MG v. 25, n. 3, p. 621-628, 2007 
where the herbicide was applied directly on bare soil or covered with straw. Thus, for I. grandifolia, B. plantaginea and B. decumbens, the highest control levels were obtained when the herbicide reached the soil directly as well as leached through the straw by simulated rainfall after application.

Keywords: herbicide; leaching; raw sugar cane; effectiveness.

\section{INTRODUÇÃO}

A palha é apenas uma das barreiras para o uso de herbicidas com ação exclusiva ou preferencial no solo. O acréscimo do teor superficial de matéria orgânica no solo - menos evidente em cana-crua do que em plantio direto - em função da movimentação mínima no momento da colheita mecanizada, associada ao preparo e sulcamento por ocasião da nova implantação da cultura, propicia a adsorção dos herbicidas, limitando a sua eficiência (Tofoli, 2004). Embora o solo esteja coberto com uma camada de palha, sabe-se que determinadas espécies de plantas daninhas, ao germinarem, vão vencer essa barreira física e vão se estabelecer no canavial, o que pode ser resultado do fato de alguns herbicidas serem mais retidos pela cobertura morta (Rossi, 2004) e, conseqüentemente, terem sua eficácia reduzida.

Quando um herbicida é aplicado sobre a palhada, é interceptado pela superficie da palha ali depositada e torna-se vulnerável à degradação causada pela volatilização e/ou fotodecomposição, até ser lixiviado para o solo (Locke \& Bryson, 1997). Lamoreaux \& Hess (1993) ressaltam que a lavagem de herbicidas da palha para o solo é dependente da capacidade desses resíduos em cobrir o solo e reter os herbicidas; da solubilidade do produto aplicado; e do período em que a área permanece sem chuva após a aplicação do produto. A partir do momento em que esses herbicidas atingem o solo apresentam maior distribuição e persistência, devido aos canais formados pelos restos vegetais (formando vias preferenciais de escoamento) ou por organismos do solo (minhocas) e, principalmente, pela amenização dos processos de degradação (Jones et al., 1990; Sorenson et al., 1991).

$\mathrm{Na}$ colheita de cana-crua, são deixadas sobre o solo de 5 a 20 toneladas de palha por hectare. A quantidade de palha é função direta das características da variedade, como facilidade de despalha do colmo, hábito de crescimento da touceira, uniformidade em altura e tamanho dos ponteiros, produtividade e desenvolvimento da cana (Manechini, 1997). A palha afe ta drasticamente o estabelecimento de plantas daninhas em áreas cultivadas, de diferentes maneiras. Dentre elas, citam-se a limitação de variação da temperatura na superficie do solo; a formação de uma barreira física a ser transposta pela planta em germinação; o aumento da quantidade de microrganismos que podem decompor as sementes dessas plantas; e os possiveis efeitos alelopáticos que inibem a germinação. Apesar disso, algumas plantas daninhas, como Ipomoea grandifolia e Euphorbia heterophylla, não têm sua germinação inibida pelas quantidades de palha de cana-de-açúcar que normalmente são encontradas em campo (Martins et al., 1999; Velini \& Negrisoli, 2000).

Correia \& Durigan (2004) estudaram os efeitos da cobertura do solo, com 0, 5, 10 e $15 \mathrm{t}$ ha ${ }^{1}$, sobre a emergência de seis espécies de plantas daninhas (Brachiaria decumbens, Digitaria horizontalis, Sida spinosa, Ipomoea grandifolia, Ipomoea hederifolia e Ipomoea quamoclit), na qual se constatou que a cobertura do solo com 5, 10 e $15 \mathrm{t} \mathrm{ha}^{-1}$ inibiu a emergência de plântulas das espécies $B$. decumbens e $S$. spinosa, sendo o mesmo observado para D. horizontalis submetida a 10 e $15 \mathrm{t} \mathrm{ha}^{-1}$. No entanto, para I. grandifolia e I. hederifolia, o número de plantas emersas não diferiu entre as quantidades de palha. Por sua vez, a presença da cobertura morta com palha de cana incrementou a emergência de plântulas de I. quamoclit. Após remoção da palha, não foram verificados fluxos expressivos na emergência de plântulas das espécies estudadas.

Assim, o objetivo deste trabalho foi avaliar a eficácia de tebuthiuron em vaso, quando aplicado em diferentes posicionamentos em 
relação à camada de palha de cana-de-açúcar, e seu comportamento diante do efeito da chuva simulada antes ou após a aplicação do herbicida.

\section{MATERIAL E MÉTODOS}

O experimento foi realizado no Núcleo de Pesquisas Avançadas em Matologia (NuPAM), pertencente ao Departamento de Produção Vegetal da Faculdade de Ciências Agronômicas/Unesp-Botucatu/SP.

O solo utilizado foi inicialmente seco à sombra por um período de 48 horas. Após esse periodo, foi peneirado em peneira com malha de 200 mesh e submetido às análises química (Tabela 1) e granulométrica, sendo classificado como solo de textura média. Foi realizada a adubação de acordo com o resultado da análise, para propiciar melhor germinação das plantas daninhas. Em seguida, o solo foi acondicionado em vasos de $2 \mathrm{~L}$ de capacidade, procedendo-se à semeadura com as espécies $B$. plantaginea, $B$. decumbens e $I$. grandifolia. O experimento foi conduzido em delineamento inteiramente casualizado, com quatro repetições, incluindose testemunhas com e sem a palha da canade-açúcar, para avaliação da eficácia agronômica do herbicida Combine 500 SC (tebuthiuron). A umidade do solo, medida gravimetricamente, foi mantida durante todo o ensaio em dois terços da capacidade de campo.

A palha de cana-de-açúcar utilizada no experimento foi a variedade SP 80-1816, na quantidade de $5 \mathrm{t}$ de palha ha ${ }^{-1}$. Ela foi selecionada em função das informações disponiveis na literatura e de estudos anteriormente realizados, indicando ser essa quantidade uma das condições mais críticas em termos de manejo de plantas daninhas em cana-crua, uma vez que é insuficiente para controlar adequadamente as plantas daninhas, mas o bastante para reter quase que completamente a quantidade de calda aplicada (Velini \&
Negrisoli, 2000; Medeiros, 2002; Veiga Filho, 2002).

A pulverização do herbicida e a simulação de chuva foram realizadas por meio de um equipamento instalado em laboratório do NuPAM, o qual é constituído de uma estrutura metálica com $3 \mathrm{~m}$ de altura por $2 \mathrm{~m}$ de largura, que permite acoplamento de um "carrinho" suspenso a 2,5 $\mathrm{m}$ de altura. A esse carrinho encontram-se acopladas duas barras de pulverização, uma responsável pelo sistema de simulação de chuva e a outra pelo sistema de pulverização de defensivos agrícolas, as quais se deslocam por uma área útil de $6 \mathrm{~m}^{2}$ no sentido do comprimento do equipamento.

A simulação da chuva foi feita utilizandose uma bomba hidráulica de pressão constante e acionamento automático, a qual bombeia água armazenada de um reservatório, com capacidade para $1.000 \mathrm{~L}$, até a barra e as pontas de pulverização responsáveis pela formação de gotas de chuva. A barra de simulação de chuva situada a 1,45 m de altura, em relação à superficie das unidades experimentais, é constituída por três bicos de pulverização TK-SS20 de alta vazão, espaçados de $0,5 \mathrm{~m}$ e posicionados de forma a propiciar maior uniformidade de precipitação na área aplicada. Esse sistema foi operado com velocidade de deslocamento de $0,187 \mathrm{~km} \mathrm{~h}^{-1}$, o que correspondeu a 2,5 Hertz no modulador de freqüência e pressão de trabalho de $0,81 \mathrm{kgf} \mathrm{s}^{-2}$.

A barra de pulverização é constituída por quatro pontas de pulverização XR 11002 VS, espaçadas de $0,5 \mathrm{~m}$ e posicionadas a $0,5 \mathrm{~m}$ de altura em relação à superficie das unidades experimentais. Para as pulverizações do herbicida, o sistema foi operado com velocidade de deslocamento de $3,6 \mathrm{~km} \mathrm{~h}^{-1}$, o que correspondeu a 45,0 Hertz no modulador de freqüência, com consumo de calda correspondente a $200 \mathrm{~L} \mathrm{ha}^{-1}$. O equipamento foi operado sob pressão constante de 1,5 bar, pressurizado por

Tabela 1 - Resultados da análise química da amostra de solo utilizado nos vasos

\begin{tabular}{|c|c|c|c|c|c|c|c|c|c|c|}
\hline \multirow{2}{*}{ Solo } & PH & $\mathrm{MO}$ & P res. $\mathrm{Mg}$ & $\mathrm{K}^{+}$ & $\mathrm{Ca}^{+2}$ & $\mathrm{Mg}^{+2}$ & $\mathrm{H}^{+}+\mathrm{Al}^{+3}$ & SB & $\mathrm{T}$ & \multirow{2}{*}{$\begin{array}{c}\mathrm{V} \\
(\%)\end{array}$} \\
\hline & $\mathrm{CACL}_{2}$ & $\left(\mathrm{~g} \mathrm{dm}^{-3}\right)$ & $\left(\mathrm{dm}^{-3}\right)$ & \multicolumn{6}{|c|}{$\left(\mathrm{Mmol}_{\mathrm{c}} \mathrm{dm}^{-3}\right)$} & \\
\hline $\mathrm{LVd}$ & 4,3 & 19 & 1 & 0,6 & 10 & 4 & 58 & 14,6 & 73 & 21 \\
\hline
\end{tabular}

Realizada pelo Departamento de Solos - FCA/UNESP-Botucatu. 
ar comprimido. A dose de tebuthiuron aplicada foi de $1.000 \mathrm{~g} \mathrm{ha}^{-1}$.

Os tratamentos que foram conduzidos constaram de diferentes posicionamentos do herbicida e condições de umidade antes e após a aplicação. O tratamento 1 constou de cobertura de palha seca $\left(5 \mathrm{t} \mathrm{ha}^{-1}\right)$ sobre o solo seco antes da aplicação do herbicida, simulandose uma chuva de $30 \mathrm{~mm}$ depois de 24 horas da aplicação; no tratamento 2, simulou-se uma chuva de $30 \mathrm{~mm}$ sobre o solo seco, antes da cobertura com a palha seca $\left(5 \mathrm{t} \mathrm{ha}^{-1}\right)$, e foi feita aplicação do herbicida após; o tratamento 3 constou do tratamento 2 , porém foi simulado um orvalho todos os dias, pela manhã até o final do ensaio; no tratamento 4 , simulou-se uma chuva de $30 \mathrm{~mm}$ no solo seco antes da cobertura com palha seca ( $\left.5 \mathrm{t} \mathrm{ha}^{-1}\right)$, e a aplicação do herbicida foi feita em pós-emergência, quando as plântulas estavam com 2 a 4 folhas (18 DAA dos demais tratamentos); no tratamento, 5 foi realizada a chuva de $30 \mathrm{~mm}$ sobre o solo seco e aplicou-se o herbicida antes da cobertura com a palha seca $\left(5 \mathrm{t} \mathrm{ha}^{-1}\right)$; o tratamento 6 constou de cobertura do solo seco com a palha seca $\left(5 \mathrm{t} \mathrm{ha}^{-1}\right)$, sendo simulada uma chuva de $30 \mathrm{~mm} 12$ horas antes da aplicação do herbicida; no tratamento 7 , foi feita a cobertura com palha seca sobre o solo seco $\left(5 \mathrm{t} \mathrm{ha}^{-1}\right)$ antes da aplicação do herbicida e realizou-se uma chuva de $2,5 \mathrm{~mm}$ logo depois; o tratamento 8 constou da testemunha com palha seca ( $5 \mathrm{t} \mathrm{ha}^{-1}$ ) e sem aplicação; no tratamento 9, foi feita a aplicação em pré-emergência do herbicida em solo sem cobertura de palha; e o tratamento 10 constou da testemunha sem cobertura de palha e sem aplicação.

Foram realizadas avaliações visuais de controle das plantas daninhas aos $7,14,21,28$, 35, 42, 49 e 56 dias após a aplicação (DAA) e de biomassa seca aos 56 DAA. O tratamento com aplicação em pós-emergência foi iniciado aos 18 DAA dos demais tratamentos.

O delineamento experimental foi o inteiramente casualizado, com 10 tratamentos e quatro repetições; os resultados foram submetidos à análise de variância pelo teste $\mathrm{F}$, sendo suas médias comparadas pelo teste $t$ a $10 \%$ de probabilidade.

As porcentagens de controle obtidas nas avaliações foram correlacionadas com a escala de notas da Asociación LatinoAmericana de Malezas (ALAM, 1974), que atribui nota de controle de 0 a $100 \%$, bem como o seu conceito de controle, que varia de 1 (nenhum a pobre) a 6 (excelente).

Após a última avaliação, aos 56 DAA, os vasos foram desmontados e as plantas restantes colocadas em estufa para obtenção da matéria seca em cada tratamento.

\section{RESULTADOS E DISCUSSÃO}

Nas Tabelas 2 e 3 são apresentadas as porcentagens médias de controle e suas respectivas notas, para as espécies avaliadas nas diferentes épocas de avaliação.

Para I. grandifolia, todos os tratamentos apresentaram excelente nivel de controle, obtendo nota 6, já a partir dos 28 DAA (Tabela 2). Nessa espécie, os sintomas de intoxicação foram observados logo aos 7 DAA, exceto quando o tebuthiuron foi aplicado em pós-emergência, no estádio inicial de desenvolvimento da planta daninha (2-4 folhas).

Na condição de aplicação do produto sobre a palha e sem chuva depois (tratamento 2) e para o tratamento 3, com aplicação de orvalho diário, observou-se excelente controle (nota 6) em ambos os tratamentos já aos 14 DAA.

O tratamento 4, aplicado em pós-emergência das plantas daninhas (2-4 folhas), aos 18 dias após a aplicação dos demais tratamentos, demonstrou controle de $84 \%$ já aos 21 DAA (3 DAA em pós), havendo evolução dos sintomas de intoxicação, chegando a um controle excelente (nota 6) aos 28 DAA (10 DAA em pós), proporcionando $100 \%$ de controle até os 56 DAA (38 DAA em pós). No tratamento 6, em que o herbicida foi aplicado em palha úmida, o controle também foi aumentando no decorrer da condução do ensaio, chegando a muito bom (nota $5 ; 89 \%)$ aos 14 DAA e excelente dos 21 aos 56 DAA (nota 6). Negrisoli et al. (2004) também observaram que a aplicação de sulfentrazone sobre a palha de cana resultou em excelente controle (100\% aos 28 dias após a aplicação) da espécie $I$. grandifolia, no caso de ocorrência de ocorrência de chuva de $20 \mathrm{~mm}$ um dia após a aplicação.

Para B. plantaginea (Tabelas 2 e 3), os melhores tratamentos foram aqueles em que o 

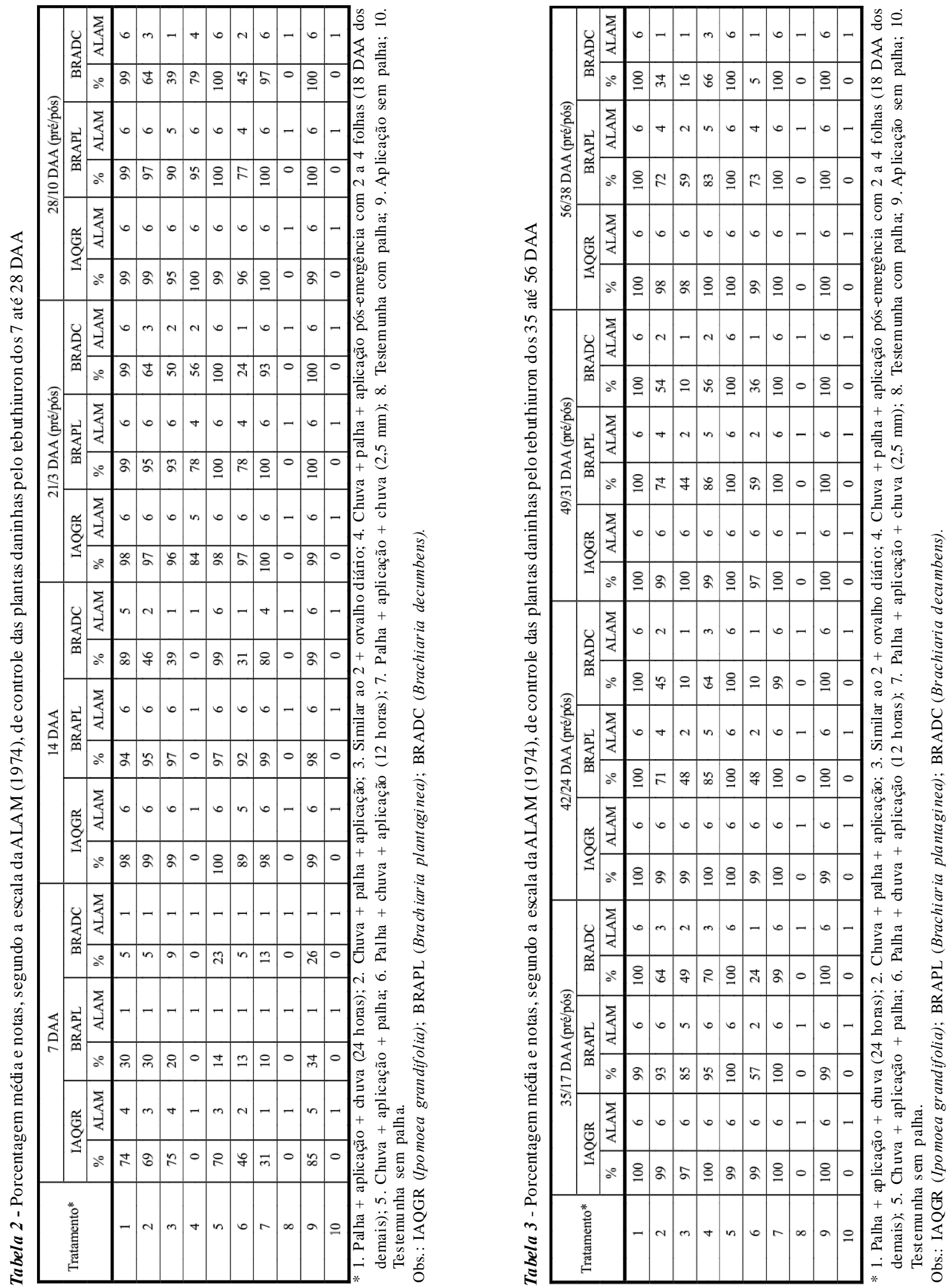
herbicida foi aplicado diretamente no solo, recebendo (tratamento 5) ou não (tratamento 9) uma camada de palha de $5 \mathrm{t} \mathrm{ha}^{-1}$ sobre o solo, e os tratamentos em que o herbicida foi aplicado sobre a palha, recebendo chuva de $2,5 \mathrm{~mm}$ (tratamento 7) ou $30 \mathrm{~mm}$ (tratamento 1) após a aplicação.

A condição de aplicação sobre a palha e sem chuva após a aplicação (tratamento 2) chegou a proporcionar excelente controle (nota 6) aos 14 DAA, porém aos 56 DAA chegou a bom (nota $4 ; 72 \%$ ). Já para o tratamento 3 com aplicação diária de orvalho sobre a palha, a eficácia diminuiu a partir dos 21 DAA, chegando a regular (nota $2 ; 59 \%$ ) aos 56 DAA. No tratamento 6 , em que se aplicou o produto em palha úmida, o controle alcançou a $97 \%$ (excelente, nota 6 , aos $21 \mathrm{DAA}$ ), chegando a bom (nota $4 ; 73 \%$ ) aos 56 DAA. A condição de aplicação em pósemergência da planta daninha (tratamento 4), aos 18 DAA dos demais tratamentos, demonstrou controle de $78 \%$ aos 21 DAA (3 DAA em pós) sobre $B$. plantaginea, havendo incremento para controle excelente (95\%; nota 6) aos 28 (10 DAA em pós) e 35 DAA (17 DAA em pós); contudo, dos 42 (24 DAA em pós) até os 56 DAA (38 DAA em pós), ocorreu queda no controle para muito bom (nota 5 ).

Para B. decumbens (Tabelas 2 e 3), os melhores tratamentos foram aqueles em que o herbicida foi aplicado diretamente no solo, recebendo (tratamento 5) ou não (tratamento 9) uma camada de palha de $5 \mathrm{t} \mathrm{ha}^{-1}$ sobre o solo, o tratamento onde o herbicida foi aplicado sobre a palha recebendo chuva de $30 \mathrm{~mm}$ após a aplicação (tratamento 1) e o tratamento 7 , onde o herbicida foi aplicado sobre a palha, recembendo chuva de $2,5 \mathrm{~mm}$. Estes tratamentos apresentaram excelente controle (nota 6) já aos $21 \mathrm{DAA}$, permanecendo inalterado até a última avaliação, aos 56 DAA. O tratamento 4, em que o herbicida foi aplicado em pósemergência (tratamento 4), apresentou controle bom (79\%; nota 4) aos 28 DAA (10 DAA em pós), porém dos 35 DAA (17 DAA em pós) até os 56 DAA (38 DAA em pós) ocorreu queda no controle para suficiente (nota 3 ).

Os tratamentos 2, com aplicação sobre a palha e sem chuva; 3 , com orvalho diário; e 6 , com palha úmida e aplicação, foram os que proporcionaram os menores controles do herbicida sobre $B$. decumbens, quando comparado aos demais tratamentos. As porcentagens máximas de controle para esses tratamentos foram de $64 \%$ (nota 3 - suficiente) dos 21 aos 35 DAA para o tratamento 2; 50\% (nota 2 - regular) aos 21 DAA para o tratamento 3; e 45\% (nota 2 - regular) aos 28 DAA para o tratamento 6.

$\mathrm{Na}$ Tabela 4 são apresentados os resultados médios obtidos para matéria seca total de cada espécie de planta daninha em cada tratamento, aos 56 DAA.

Para as plantas daninhas $B$. decumbense B. plantaginea, os tratamentos 1, 5, 7 e 9 foram os que apresentaram melhores porcentagens médias de controle $(100 \%$ aos $56 \mathrm{DAA})$, provavelmente por serem os tratamentos em que o herbicida normalmente atingiu o solo, através da aplicação direta sobre este ou através da lixiviação deste herbicida pela simulação de chuva após sua aplicação. Esses resultados demonstram a importância e a necessidade da ocorrência de chuva após aplicação do herbicida sobre a palha, podendo lixiviar quantidade suficiente de tebuthiuron da palha para o solo, o que pode ser explicado ainda pela absorção preferencial do produto via radicular. Já para

Tabela 4 - Peso da biomassa seca total (g), aos 56 DAA. Botucatu, 2003

\begin{tabular}{|c|c|c|c|}
\hline \multirow{2}{*}{ Tratamento* } & \multicolumn{3}{|c|}{ Peso da biomassa seca total (g) } \\
\cline { 2 - 4 } & IAQGR & BRAPL & BRADC \\
\hline 1 & $0,000 \mathrm{C}$ & $0,000 \mathrm{C}$ & $0,000 \mathrm{E}$ \\
\hline 2 & $0,009 \mathrm{C}$ & $2,485 \mathrm{~B}$ & $3,251 \mathrm{D}$ \\
\hline 3 & $0,010 \mathrm{C}$ & $2,999 \mathrm{~B}$ & $9,159 \mathrm{C}$ \\
\hline 4 & $0,007 \mathrm{C}$ & $1,379 \mathrm{~B}$ & $1,432 \mathrm{DE}$ \\
\hline 5 & $0,000 \mathrm{C}$ & $0,000 \mathrm{C}$ & $0,000 \mathrm{E}$ \\
\hline 6 & $0,004 \mathrm{C}$ & $2,924 \mathrm{~B}$ & $11,229 \mathrm{BC}$ \\
\hline 7 & $0,000 \mathrm{C}$ & $0,000 \mathrm{C}$ & $0,000 \mathrm{E}$ \\
\hline 8 & $2,627 \mathrm{~B}$ & $6,598 \mathrm{~A}$ & $21,216 \mathrm{~A}$ \\
\hline 9 & $0,000 \mathrm{C}$ & $0,000 \mathrm{C}$ & $0,000 \mathrm{E}$ \\
\hline 10 & $4,134 \mathrm{~A}$ & $5,705 \mathrm{~A}$ & $13,533 \mathrm{~B}$ \\
\hline $\mathrm{CV}(\%)$ & 175,47 & 92,88 & 44,56 \\
\hline $\mathrm{dms}(\mathrm{g})$ & 1,430 & 2,462 & 3,199 \\
\hline
\end{tabular}

${ }^{1}$ Médias seguidas das mesmas letras não diferem estatisticamente entre si pelo teste $\mathrm{t}$ a $10 \%$ de probabilidade.

* 1. Palha + aplicação + chuva (24 horas); 2. Chuva + palha + aplicação; 3. Similar ao $2+$ orvalho diário; 4 . Chuva + palha + aplicação pós-emergência com 2 a 4 folhas (18 DAA dos demais); 5. Chuva + aplicação + palha; 6 . Palha + chuva + aplicação $(12$ horas); 7. Palha + aplicação + chuva $(2,5 \mathrm{~mm}) ; 8$. Testemunha com palha; 9. Aplicação sem palha; 10. Testemunha sem palha. Obs.: IAQGR (Ipomoea grandifolia); BRAPL (Brachiaria plantaginea); BRADC (Brachiaria decumbens). 
I. grandifolia, além dos tratamentos citados, a aplicação em pós-emergên cia da planta daninha (tratamento 4) apresentou $100 \%$ de controle aos 56 DAA. Rossi et al. (2004), estudando a associação do metribuzin à palha de cana-de-açúcar na eficácia de controle de plantas daninhas, observaram que o produto foi eficaz em todos os posicionamentos, quando associado à palha de cana-de-açúcar.

Pela análise da Tabela 4, pode-se observar que todos os tratamentos com aplicação do herbicida resultaram na redução total da matéria seca das plantas de $I$. grandifolia. Para B. plantaginea, os tratamentos 5 e 9 , com aplicação sobre o solo e cobertura ou não de palha após aplicação, e os tratamentos 1 e 7 , com aplicação na palha e chuva de 30 ou 2,5 $\mathrm{mm}$ após aplicação, resultaram na redução total das plantas.

Em B. decumbens, os tratamentos 5 e 9, com aplicação sobre o solo e cobertura ou não de palha após a aplicação, e os tratamentos 1 e 7, com aplicação na palha e chuva de $30 \mathrm{ou}$ $2,5 \mathrm{~mm}$ após aplicação, resultaram na redução total das plantas. $O$ tratamento 4, aplicação em pós-emergência, não reduziu totalmente a biomassa das plantas, mas não diferiu estatisticamente dos tratamentos 1, 2, 5, 7 e 9. Os tratamentos 2 (aplicação em palha seca e sem chuva após), 3 (orvalho diário) e 6 (aplicação em palha úmida) foram os que apresentaram maior biomassa seca de $B$. decumbens, mas ainda diferiram estatisticamente da testemunha com palha.

As testemunhas com palha (tratamento 8) e sem palha (tratamento 10) diferiram estatisticamente nas espécies estudadas. A espécie I. grandifolia apresentou estímulo no desenvolvimento na ausência da cobertura de palha (tratamento 9); comportamento contrário foi observado para a espécie $B$. decumbens, porém, para $B$. plantaginea, não ocorreu diferença entre as testemunhas com e sem palha.

Portanto, a espécie I. grandifolia mostrouse a mais sensivel ao tebuthiuron, com alta porcentagem de controle em todos os tratamentos estudados. Para $B$. plantaginea e $B$. decumbens, as porcentagens de controle foram altas nos tratamentos em que o herbicida chegou ao solo (tratamentos 1, 5, 7 e 9), independentemente se aplicado diretamente sobre este ou lixiviado pela simulação de chuva após aplicação do herbicida. Os resultados encontrados estão de acordo com Costa (2001), o qual relata que, para exercerem sua atividade sobre as plantas infetantes, os herbicidas residuais precisam ser introduzidos diretamente no solo, o que se dá através do carreamento pela chuva, em função da solubilidade do produto.

\section{LITERATURA CITADA}

CORREA, M. M.; DURIGAN, J. C. Emergência de plantas daninhas em solo coberto com palha de cana-de-açúcar.

Planta Daninha, v. 22, n. 1, p. 11-17, 2004.

COSTA. E. A. D. Efeito de adjuvantes na dinâmica de ametryn em palha de cana-de-açúcar. 2001. $81 \mathrm{f}$. Tese (Doutorado em Proteção de Plantas/Produção Vegetal) Universidade Estadual Paulista, Botucatu, 2001.

JONES JR, R.E.; BANKS, P. A.; RADCLIFFE, D. E. Alachlor and metribuzin movement and dissipation in a soil profile as influenced by soil surface condition. Weed Sci., v. 38, p. 589-597, 1990.

LAMOREAUX, R. J.; JAIN, R.; HESS, F. D. Efficacy of dimethenamid, metolachlor and encapsulated alachlor in soil covered with crop residue. In: BRIGHTON CROP PROTECTION CONFERENCE - XX. Weeds, v. 3, p. 1015-1220, 1993.

LOCKE, M. A.; BRYSON, C. T. Herbicide-soil interaction in reduced tillage and plant residue management systems. Weed Sci., v. 45, p. 307-320, 1997.

MANECHINI, C. Manejo da cana crua. In: SEMINÁRIO COPERSUCAR DE TECNOLOGIA AGRONÔMICA, 7., 1997, Piracicaba. Anais... Piracicaba: 1997. p. 309-27. 1997.

MARTINS, D. et al. Emergência em campo de dicotiledôneas infestantes em solo coberto com palha de cana-de-açúcar.

Planta Daninha, v. 17, n. 1, p. 151-161, 1999.

MEDEIROS, D.; CHRISTOFFOLETI, P. J. Efeito da intensidade de chuva e da quantidade de palha de cana-deaçúcar sobre a eficácia de herbicidas. In: CONGRESSO BRASILEIRO DA CIÊNCIA DAS PLANTAS DANINHAS, 23., 2002, Gramado. Anais... Londrina: IAPAR, 2002. p. 510.

NEGRISOLI, E. et al. Eficácia do sulfentrazone em diferentes doses associado à palha de cana-de-açúcar com ou sem chuva após a aplicação no controle de plantas daninhas. In: CONGRESSO BRASILEIRO DA CIÊNCIA DAS PLANTAS DANINHAS, 24., 2004, São Pedro. Anais... São Pedro: 2004. CD-ROM

ROSSI, C. V. S. et al. Associação do metribuzin à palha de cana-de-açúcar na eficácia de controle de plantas daninhas. In: CONGRESSO BRASILEIRO DA CIÊNCIA DAS PLANTAS DANINHAS, 24., 2004, São Pedro. Anais... São Pedro: 2004. CD-ROM

Planta Daninha, Viçosa-MG v. 25, n. 3, p. 621-628, 2007 
SORENSON, B. A.; SHEA, P. J.; ROETH, F. W. Effects of tillage, application time and rate on metribuzin dissipation. Weed Res., v. 31, p. 333-345, 1991.

TOFOLI, G. R. Deposição e lixiviação do herbicida tebuthiuron em palha de cana-de-açúcar. 2004. $63 \mathrm{f}$.

Tese (Doutorado em Proteção de Plantas/Produção Vegetal) Universidade Estadual Paulista, Botucatu, 2004.
VEIGA FILHO, A. Evolução da mecanização do corte da cana-de-açúcar em São Paulo. In: XIII CONGRESSO

NACIONAL DA STAB, 8., 2002, Recife. Anais... Recife: 2002. p. 515-521.

VELINI, E. D.; NEGRISOLI, E. Controle de plantas daninhas em cana crua. In: XXII CONGRESSO BRASILEIRO DA CIÊNCIA DAS PLANTAS DANINHAS, 22., 2000,

Foz de Iguaçu. Palestras... Foz de Iguaçu: 2000. p. 148-164. 